\title{
Integrating Large Wind Farms into Weak Power Grids with Long Transmission Lines
}

\author{
Richard Piwko, Fellow IEEE, Nicholas Miller, Fellow IEEE, \\ Juan Sanchez-Gasca, Fellow IEEE, Xiaoming Yuan, Renchang Dai, James Lyons
}

\begin{abstract}
In China, as in other parts of the world, many of the best resources for wind generation are located far away from load centers. Large generating facilities connected to distant load centers by long ac transmission lines face numerous technical challenges, regardless of the type of generating facility. This paper addresses some of the most significant challenges for wind generation facilities, including voltage control, reactive power management, dynamic power-swing stability, and behavior following disturbances in the power grid.

Wind generation technology has evolved significantly over the past several years, and proven solutions to these technical challenges now exist. Controls integrated into the power electronics and mechanical controls of individual wind-turbinegenerators, combined with integrated wind-farm control systems, have the capability of controlling numerous wind turbines so that they act as one unified generating plant at the point of interconnection with the power grid. This advanced hierarchical control of both real and reactive power output can provide dynamic performance that is, in many cases, superior to that achievable with modern conventional synchronous generation. This paper describes:
\end{abstract}

a. Wind farm control functions, including performance for controlling grid voltage in quasi-steady-state and dynamic conditions.

b. Low-voltage ride-through characteristics, including performance following severe system disturbances

c. Dynamic power control functions within wind turbinegenerators, including transient and dynamic performance for power swings.

Index Terms-Wind Generation, Wind Farm Integration, Low Voltage Ride Through, LVRT, Voltage Regulation, Power Swings.

\section{INTRODUCTION}

Integration of large wind farms into bulk power systems presents multiple challenges to system operation and security. One particular challenge to system security is vulnerability to common-mode tripping due to transmission system faults. Wind generators may have to be disconnected from the grid once the system has a disturbance, such as a short circuit fault, lightning strike on transmission lines, etc. Tripping generators normally has a negative impact on system stability, especially when wind farms have considerable penetration. This is a major concern throughout the world. Furthermore many wind farms, including proposed large offshore projects, are geographically remote and have relatively weak transmission

R.J. Piwko is with GE Energy, One River Road, Schenectady, New York, USA (email: richard.piwko@ge.com) systems. The presence of wind farms in such weak systems raises serious concerns about system stability, voltage regulation, and post-fault power swings.

Host utilities require that, during normal operation, wind farms should be capable of regulating voltage or reactive power to maintain a smooth voltage profile at the point of interconnection, protecting against voltage flicker caused by wind gusts. With the penetration of wind farms increasing, most host utilities also require that wind farms must tolerate system disturbances. For instance, wind farms must not trip during faults and other system disturbances, and they must remain stable during post fault electromechanical swings in the power grid.

These requirements are being addressed by the latest generation of wind turbine-generator (WTG) equipment. Wind Farm Management Systems (WFMS) and Low-Voltage Ride-Through (LVRT) technology for wind turbine generators can provide much improved system performance compared to more traditional wind generation equipment. LVRT technology is now able to eliminate most concerns about tripping during system voltage events and allows for the rapid and well-behaved recovery of the wind farm and the grid when system faults are removed. Wind farms controlled by WFMS can provide extremely fast initial response to system events and wind induced perturbations, and voltage and reactive power response similar to that of conventional synchronous generation.

This paper presents dynamic performance of GE wind turbine-generators with LVRT and WFMS technology. The information presented includes dynamic simulation results from existing power systems with large wind farm interconnections, and actual field measurements from operating systems. The paper also presents control design philosophy, innovative control designs and relevant control diagrams.

\section{WIND TURBINE-GENERATOR CHARACTERISTICS}

This section presents an overview of a dynamic model of the GE 1.5 MW WTG. A detailed description of the model, including pertinent parameter values, is provided in [1]. WTG models are continually being updated and improved, as wind generation technology evolves. GE regularly updates wind modeling documents.

A simple schematic of the WTG major components is shown in Figure 1. The GE WTG generator is unusual from a system simulation perspective. Physically, the machine is a 
relatively conventional technology wound rotor induction machine. However, the key distinction is that this machine is equipped with a solid-state $\mathrm{AC}$ excitation system. The AC excitation is supplied through an ac-dc-ac converter. The fundamental frequency electrical dynamic performance of the WTG is completely dominated by the field converter. In practice, the electrical behavior of the generator and converter is that of a current-regulated voltage source inverter. Like other voltage source inverters (e.g. a BESS or a STATCOM), the converter will make the WTG behave like a voltage behind a reactance that results in the desired active and reactive current being delivered to the device terminals. Conventional aspects of generator performance related to internal angle, excitation voltage, and synchronism are largely irrelevant. These characteristics have significant implications from the standpoint of power-swing performance and modal interactions.

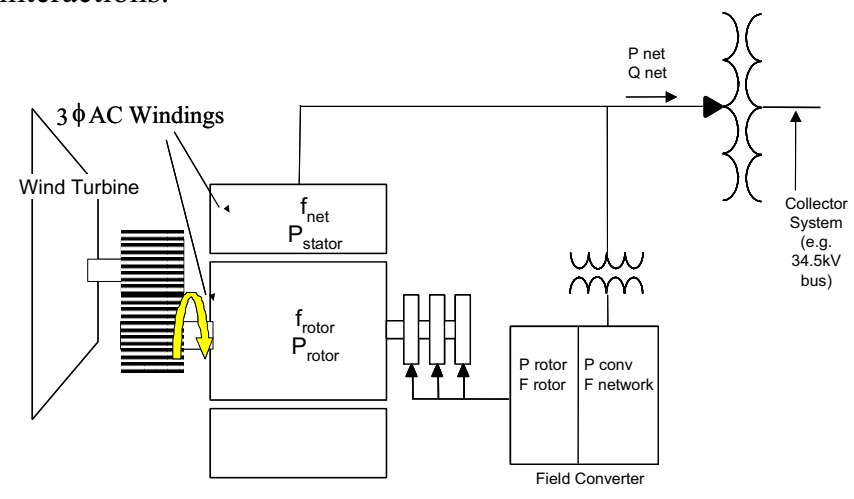

Figure 1. GE WTG Major Components. Source: GE Energy @2005. Used with Permission.

It should be noted that the wind turbine model used in this paper is based on presently available design information, test data and extensive engineering judgment. This model was developed specifically for the GE 1.5 and 3.6 MW WTGs. This model is not designed for, or intended to be used as, a general purpose WTG. There are substantial variations between models and manufacturers.

The overall WTG model consists of four major elements, as shown in Figure 2:

i) Generator/Network Interface,

ii) Electrical Control,

iii) Wind Turbine, and

iv) Wind Power Model.

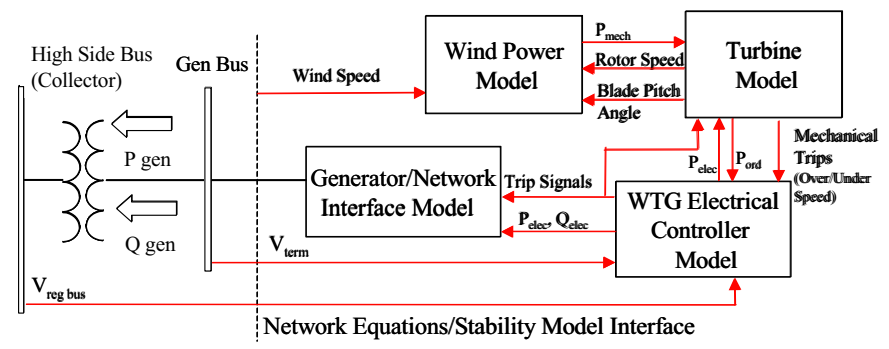

Figure 2. GE WTG Basic Dynamic Models and Data Connectivity Source: GE Energy $\mathbb{C} 2005$. Used with Permission.

\section{A. Generator/Network Interface}

This element is the physical equivalent of the generator and converter hardware. It provides the interface between the WTG electrical controller and the network, and contains no control functions or user settable functions.

\section{B. Electrical Controller}

The WTG Electrical Controller dictates the active and reactive power to be delivered to the system based on input from the turbine model and power system conditions. The model is greatly simplified, but maintains those aspects that are crucial to capturing the dynamic performance of interest to the system.

\section{Wind Turbine}

The wind turbine model provides a simplified representation of a very complex electro-mechanical system. The turbine control is designed to deliver power over a range of wind conditions, taking advantage of the variable speed capability of the machine. The controller enforces the powerspeed relationship shown in Figure 3. Above about $75 \%$ rated power, the power levels of primary interest for stability studies, the controller works in two distinct regions. When the available wind power is above the equipment rating, the blades are pitched to reduce the mechanical power (Pmech) delivered to the shaft down to the equipment rating (1.0 p.u.), thereby returning the machine to the reference speed for full power operation, $120 \%$ of synchronous speed. When the available wind power is less than rated, the blades are fixed to maximize the mechanical power, and speed control is accomplished by adjusting the generator electrical power. The dynamics of the pitch control are moderately fast, and can have significant impact on dynamic simulation results. The block diagram for the model is shown in Figure 4.

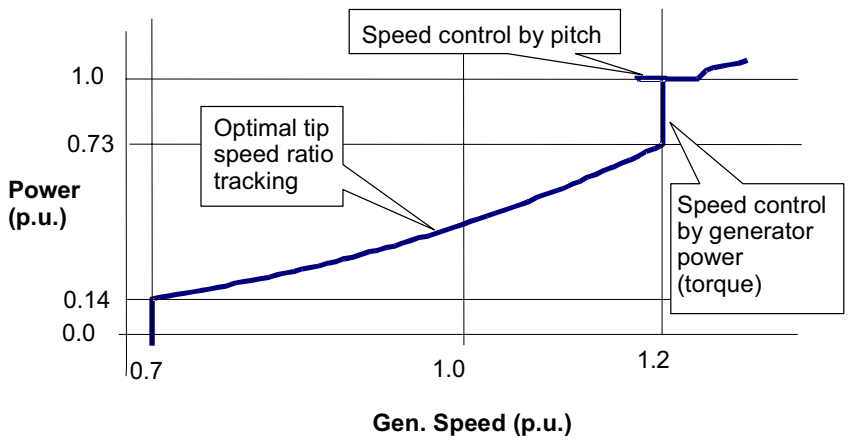

Figure 3. Power vs. Speed Steady State Curve Source: GE Energy (C2005. Used with Permission.

The wind turbine model represents all of the relevant controls and mechanical dynamics of the wind turbine. The model accepts the machine terminal active power from the WTG Electrical Control Model and the mechanical power calculated by the Wind Power Model. The turbine control model sends a power order to the electrical control for the converter to deliver the requested power to the grid. The electric power actually delivered to the grid is returned to the 
turbine model, for use in the calculation of rotor speed.

The speed controller does not differentiate between shaft acceleration due to increase in wind speed or due to system faults. In either case, the response is appropriate and relatively slow compared to the electrical control.

The turbine control acts so as to smooth out electrical power fluctuations due variations in shaft power. By allowing the machine speed to vary around its rated value $(120 \%)$, the inertia of the machine functions as a buffer to mechanical power variations.

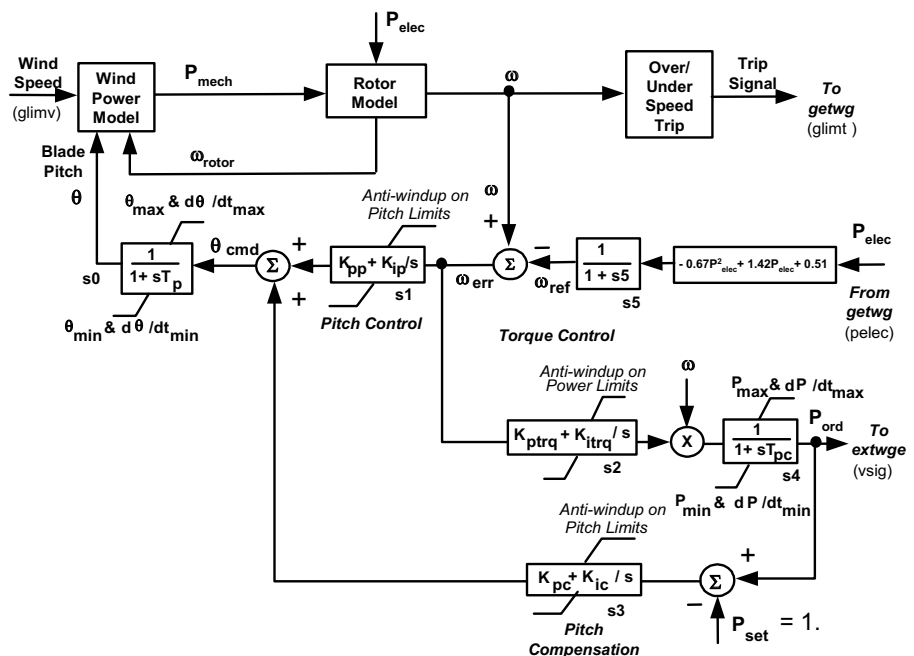

Figure 4. Wind Turbine Model Block Diagram Source: GE Energy (C2005. Used with Permission.

\section{Wind Power Model}

The function of the wind power module is to compute the wind turbine mechanical power (shaft power) from the energy contained in the wind. The well-known relationship:

$$
P=\frac{\rho}{2} A_{r} v^{3} C_{p}(\lambda, \theta)
$$

is used for this purpose. $\mathrm{P}$ is the mechanical power extracted from the wind, $\rho$ is the air density in $\mathrm{kg} / \mathrm{m}^{3}, A_{r}$ is the area swept by the rotor blades in $\mathrm{m}^{2}, v$ is the wind speed in $\mathrm{m} / \mathrm{sec}$, and $C_{p}$ is the is the power coefficient and is a function of $\lambda$ and $\theta . \lambda$ is the ratio of the rotor blade tip speed and the wind speed $\left(v_{t i p} / v\right), \theta$ is the blade pitch angle in degrees. $C_{p}$ is a characteristic of the wind turbine and is usually provided as a set of curves $\left(C_{p}\right.$ curves) relating $C_{p}$ to $\lambda$, with $\theta$ as a parameter. The $C_{p}$ curves for the GE WTG model are fit with a fourth order polynomial on $\theta$ and $\lambda$.

\section{Voltage Regulation With WFMS}

For many wind farms, including large off-shore and remote and isolated projects, traditional approaches to managing reactive power are no longer viable. Voltage and reactive power control performed by WFMS minimizes voltage flicker, improves system stability, provides voltage regulation, reduces the risk of voltage collapse, and minimizes the impact of system disruptions. WFMS provides tight closed loop control of utility system voltages. This provides two major benefits: First, the impact of active power fluctuations from wind variation on the grid voltages are minimized; second, the fast and precise voltage control effectively strengthens the grid, improving the overall power system's resilience to large disruptions.

Figure 5 shows the simulated response of a wind farm of 108 GE 1.5 MW wind turbine generators (WTGs) to ten minutes of highly variable wind near rated wind speed. The red traces show the system response with WFMS, and the black traces show the system response with conventional fixed power factor control. The fixed power factor control is local to each individual WTG. At the utility bus (the point of interconnection), the system voltage with conventional power factor (pf) control exhibits unacceptably high variation. By comparison, the WFMS controlled system voltage exhibits very small variations. The voltage flicker index, Pst, is less than 0.02 for this high stress condition - well within industry requirements.
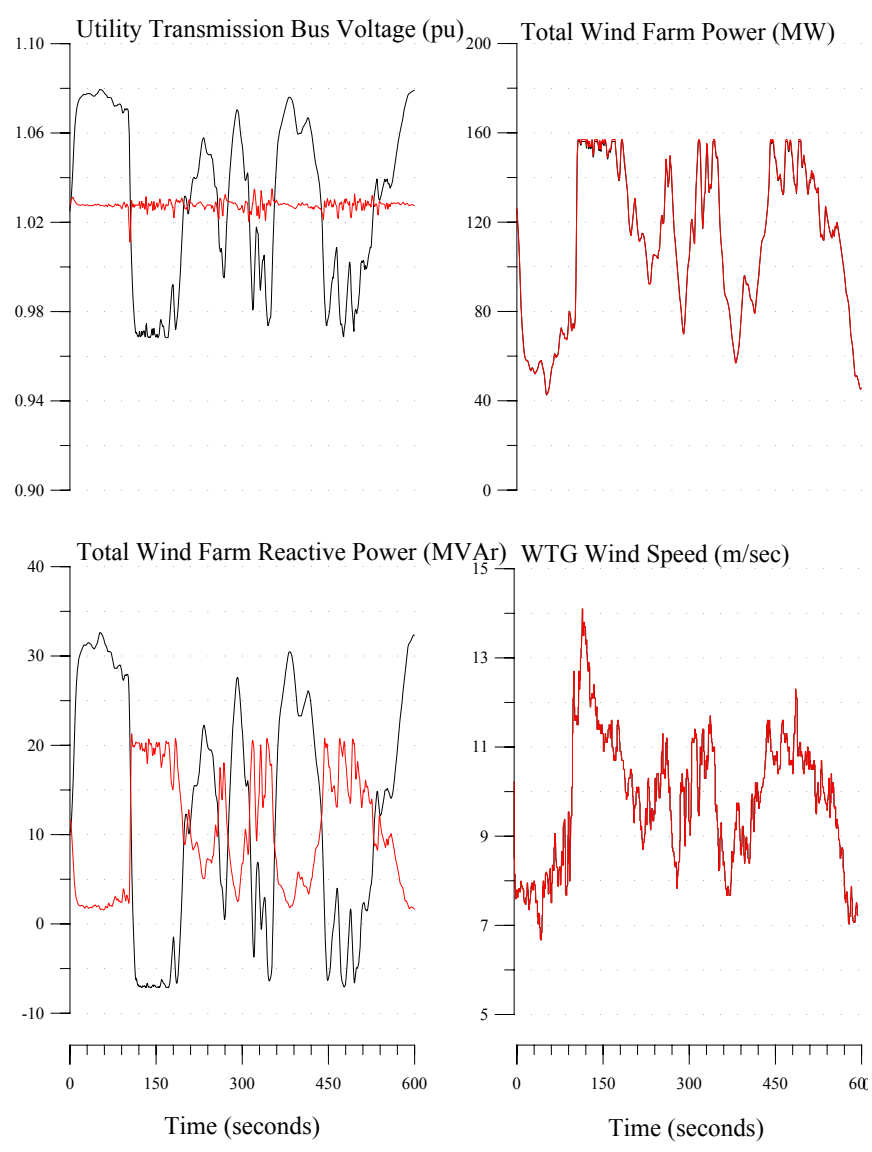

Figure 5. Simulated utility response of a large wind farm. Black traces are without WFMS (conventional fixed PF control). Red traces are with voltage control by WFMS Source: GE Energy (C2005. Used with Permission.

The variables plotted are as follows:

Utility voltage. This is the voltage at the point-of-common coupling (PCC) in p.u. For this system, the PCC is approximately $75 \mathrm{~km}$ from the wind farm.

Wind farm power. This is the total power delivered to the PCC, accounting for collector system and transmission losses. 
Wind farm reactive power. This is the total reactive power delivered to the PCC, also accounting for the reactive losses of the collector and transmission system, which are significant.

Wind speed. This is wind profile for this simulation. All the individual machines are subjected to the same wind profile in this case, which is very conservative.

The behavior of one of the WTGs for this wind profile is shown in Figure 6. The machine reactive power and terminal voltage are actively maneuvered by commands from the WFMS to produce the desired performance at the utility bus. Variables plotted include the following:

WTG terminal voltage, Vt. This is the p.u. voltage at the terminals of one of the individual wind turbine generators.

WTG speed, SPD. This is individual WTG speed variation due to wind speed variation and subject to the GE turbine control, which optimizes energy capture.

WTG reactive power, $\mathbf{Q g}$. This is the individual reactive power produced by the machine.

WTG active power, Pg. This is the individual WTG active power output. Note that it is the same either with or without the WFMS.

Figure 7 shows actual operation of the WFMS voltage regulation function at a large wind farm in the western USA. The traces cover a one-hour period where wind generation
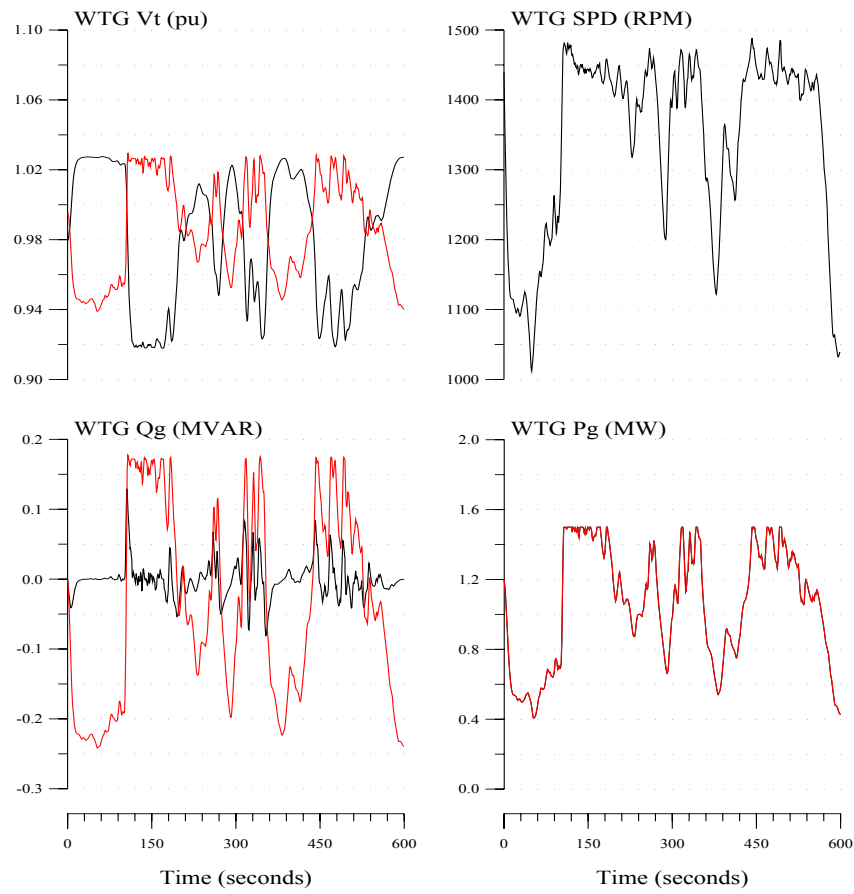

Figure 6. Simulated WTG response of a large wind farm. Black traces are without WFMS (conventional fixed PF control). Red traces are with voltage control by WFMS Source: GE Energy (C2005. Used with Permission.

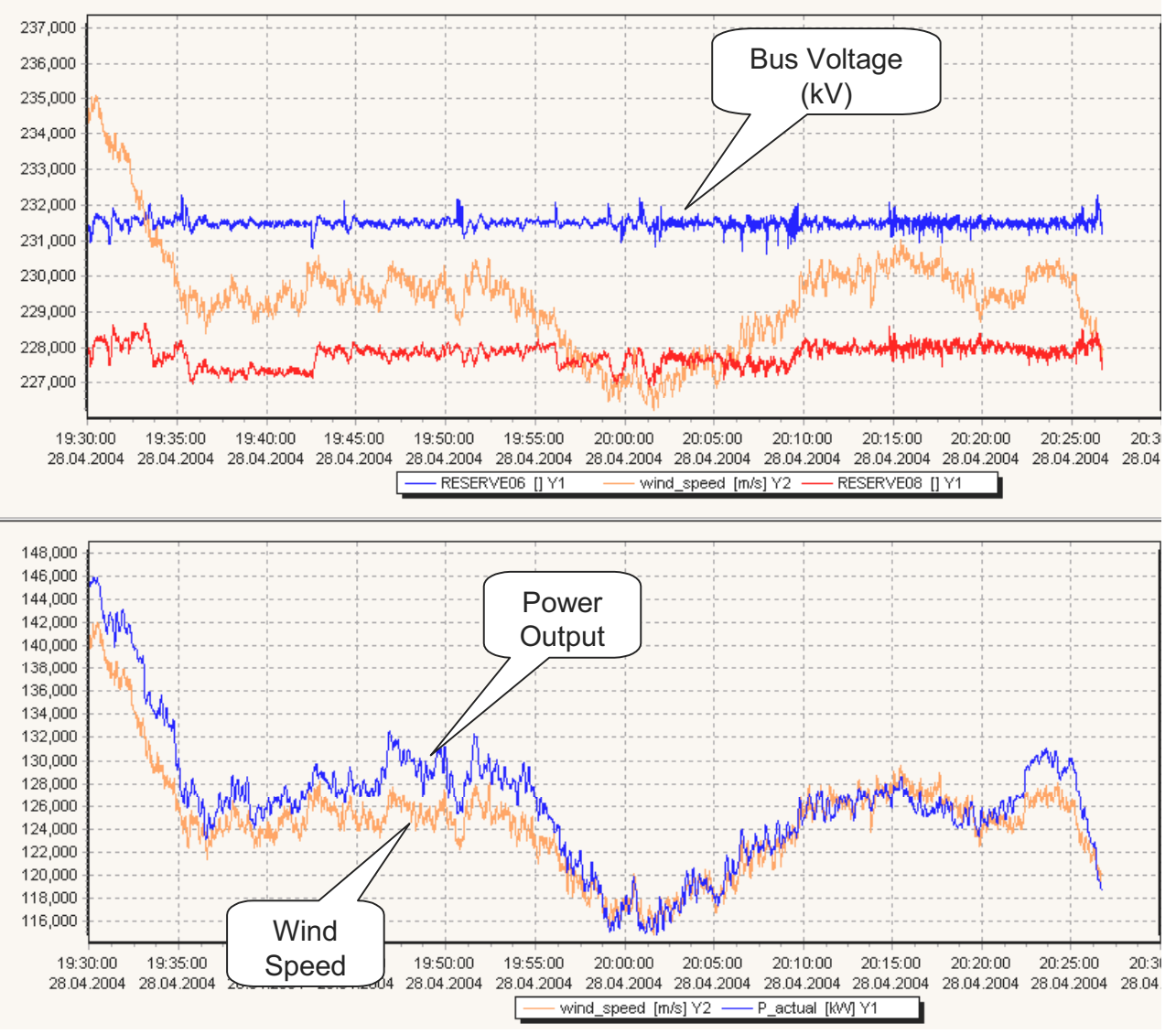

Figure 7. Measurements from Wind Farm in Western USA, April 28, 2004, 19:30 to 20:30 Source: GE Energy $@$ 2005. Used with Permission. 
varied over a range of 114 to $146 \mathrm{MW}$. During this period, the bus voltage at the $230 \mathrm{kV}$ point of interconnection remained within $1 \mathrm{kV}$ of its setpoint.

For transmission system events, the response of the WFMS promotes fast and stable recovery of system voltages following fault clearing.

\section{Disturbance Response With LVRT}

Provision of uninterrupted service has grown in importance as wind farms increase in size and comprise a larger portion of total generation on the grid. Transmission system events lightning strikes, equipment failures, and downed power lines - are common on utility grids around the world. Transmission planners and system operators expect generators to tolerate and, ideally, recover from system events. Until recently, wind turbines have been designed to trip offline in response to instantaneous voltage drops in order to protect the wind turbine equipment until the grid recovers. In tightly interconnected grids with significant penetration of wind generation, however, this response can lead to cascading failure of the entire system. GE's LVRT feature renders this over-sensitive response obsolete by improving generator and control system design. Before LVRT technology, wind turbines would trip off-line on any voltage sag below $70 \%$. Now they are designed to ride through severe grid disturbances, as illustrated by the test graphs in Figure 8.

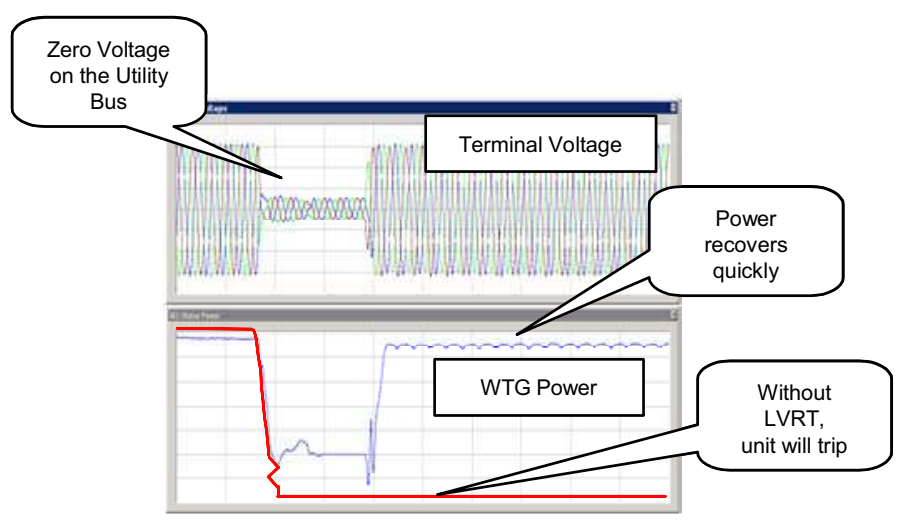

Figure 8. Equipment tests of LVRT performance. Source: GE Energy (C2005. Used with Permission.

Unbalanced faults present a particularly difficult challenge, both in terms of equipment design and system simulation. Validated simulation models are essential tools for proper equipment design and performance analysis. The traces of Figure 9 compare a factory test measurement [red traces] of LVRT for a severe unbalanced fault against the simulation model [black traces]. The results demonstrate the capability of LVRT to handle unbalanced faults and a high level of fidelity in the digital simulations and models.
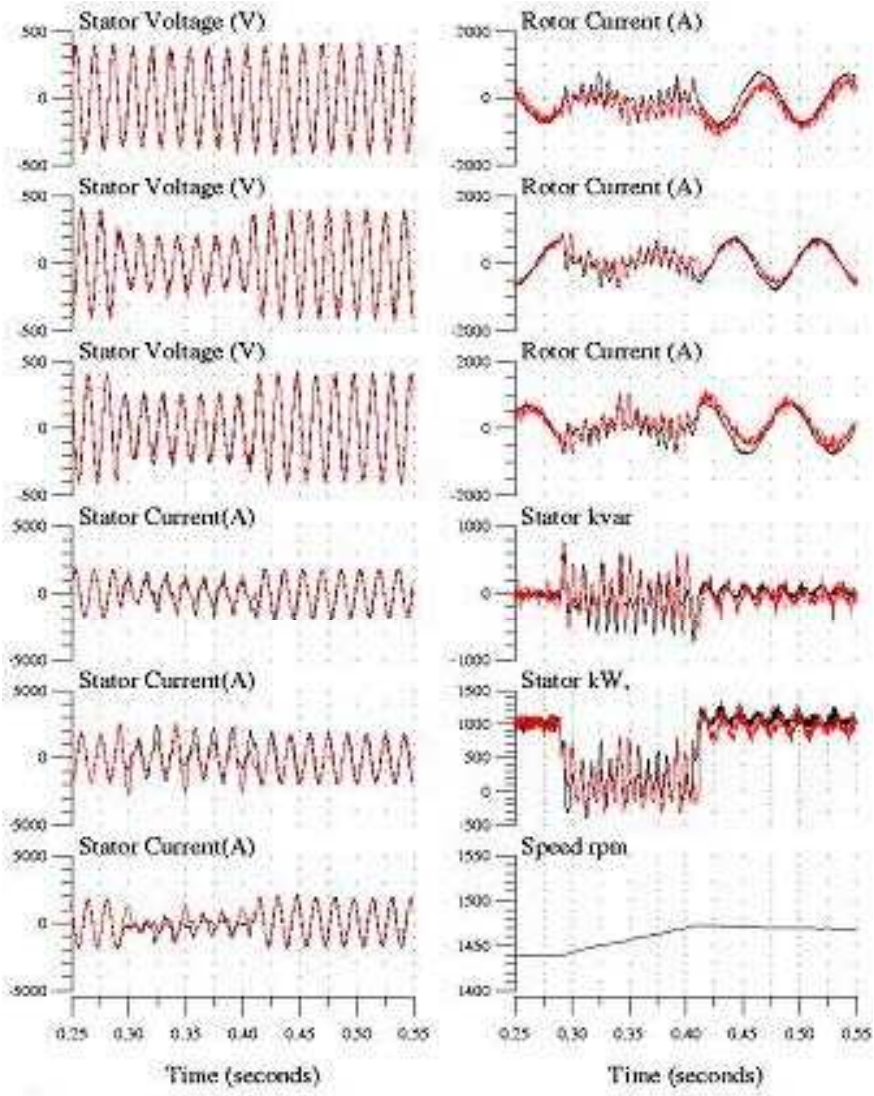

Figure 9. Unbalanced fault on GE 1.5 MW WTG - Tests and Simulation Source: GE Energy (O2005. Used with Permission.

\section{POWER-Swing Stability}

Electromechanical oscillations, or power swings, often arise between areas in large interconnected power networks and are related to the dynamics of interarea power transfers. Figure 10 shows the two-area four-generator system described in [2] that has been widely used to evaluate power swing dynamics in transmission grids. This example shows the results obtained when a wind farm, represented by an equivalent WTG, replaces one of the four generators.

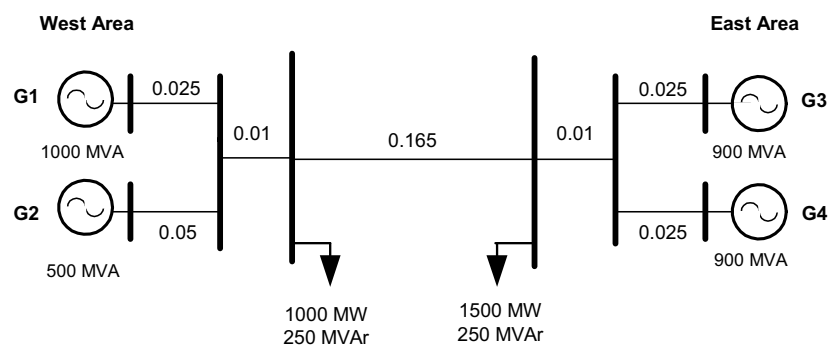

Figure 10 Four Generator Test System

In this study, G1, G3 and G4 are synchronous generators; G2 is modeled as either a synchronous generator or as a WTG. In the latter case, the single WTG represents a large wind farm. Representation of a wind farm consisting of many units by a single WTG and transformer with MVA ratings equal to the individual unit ratings, times the number of units 
in the farm, gives a reasonable equivalent for bulk system studies, since the impedance of a typical collector system is relatively small compared to the impedance of the unit transformer,

The rating of the wind farm was selected to represent a $33 \%$ penetration in the West Area. The model data are provided in [2].

\section{A. Study Approach}

The test system was analyzed at four different operating conditions. For each operating condition, the 500 MVA machine, G2, located in the West Area, was first modeled as conventional synchronous generator and then as a single WTG.

Each operating condition corresponds to a different power generation from machine G2. The power output from the WTG reflects the amount of power available for a given wind speed. The initial power output of G2 was set to $150 \mathrm{MW}$, subsequent generation levels considered were $250 \mathrm{MW}, 350$ MW and $450 \mathrm{MW}$. The dispatch from generators G1 and G4 was kept constant at 900 and $650 \mathrm{MW}$, respectively.

\section{B. Analysis}

The results of this investigation show that the interarea mode tends to become more stable as the real power dispatch of the WTG approaches its nominal value (450 MW), whereas the opposite is true for the system with the synchronous generator. These trends are shown as root locus plots in Figure 11. The inter-area mode locus for the case with the WTG is shown as a solid line. The locus for the case with the synchronous generator is shown as a dashed line. From a practical standpoint, the damping ratios for both cases exhibit a comparable range of variation $(1 \%-2.5 \%)$ as depicted in Figure 12.

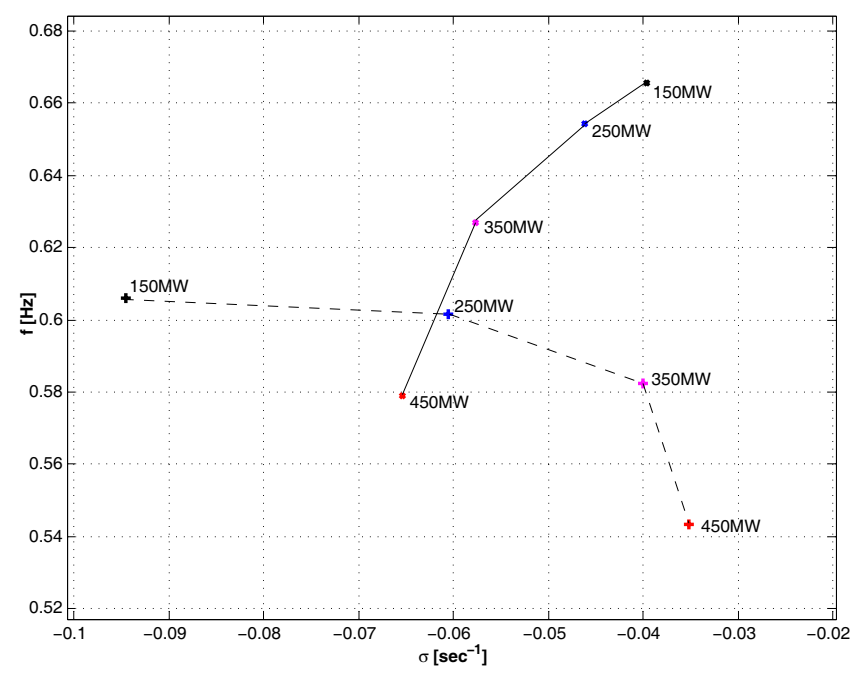

Figure 11. Root locus of interarea mode ( --- WTG, - - - Synch. Gen.) Source: GE Energy (C2005. Used with Permission.

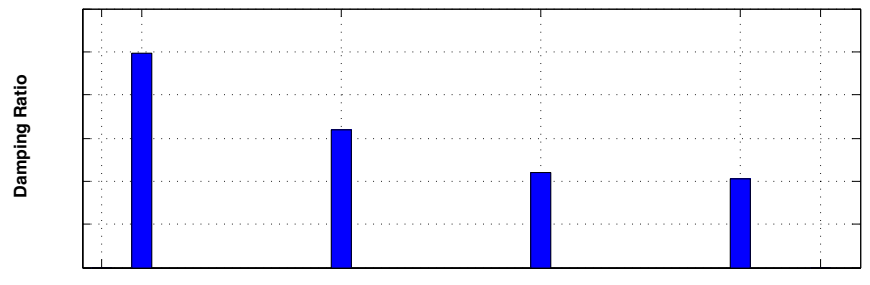

P Synch. Gen. G2 [MW]

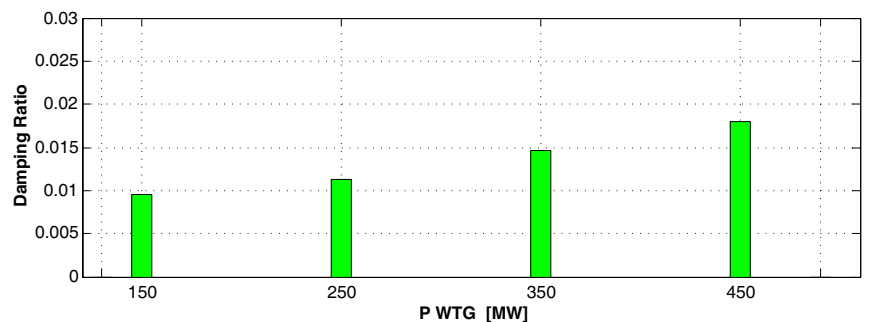

Figure 12. Damping ratios for interarea mode as G2 power output increases. Source: GE Energy (C2005. Used with Permission.

The most significant differences in the modal characteristics between the systems with the WTG and the synchronous generator arises from the fact that the WTG appears to the rest of the system as a voltage source behind an impedance, and does not interface with the network through an internal angle as a synchronous generator does. This translates in the absence of the mechanical states, speed and angle, from the right eigenvector (mode shape) associated with the inter-area mode. Furthermore, the West Area local mode does not exist when G2 is a WTG. This is illustrated in Figures 13 and 14. Figure 13 shows the local modes of the West and East Areas for the four generation levels considered, when G2 is modeled as a synchronous generator. When G2 is modeled as a WTG, only the local mode associated with the East Area is present (Figure 14).

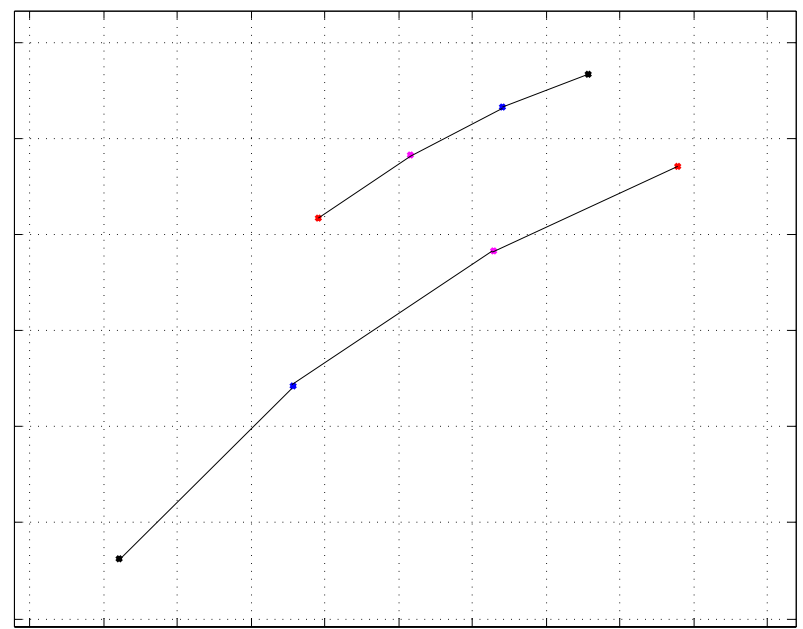

Figure 13. Local Modes when G2 is a Synchronous Generator Source: GE Energy (C2005. Used with Permission. 
For the system and cases considered, the local mode associated with the East Area tends to become less stable as the power output from $\mathrm{G} 2$ as a synchronous generator increases from $150 \mathrm{MW}$ to $450 \mathrm{MW}$ (Figure 13). With G2 as a WTG this condition does not arise since the East Area local mode is not present.

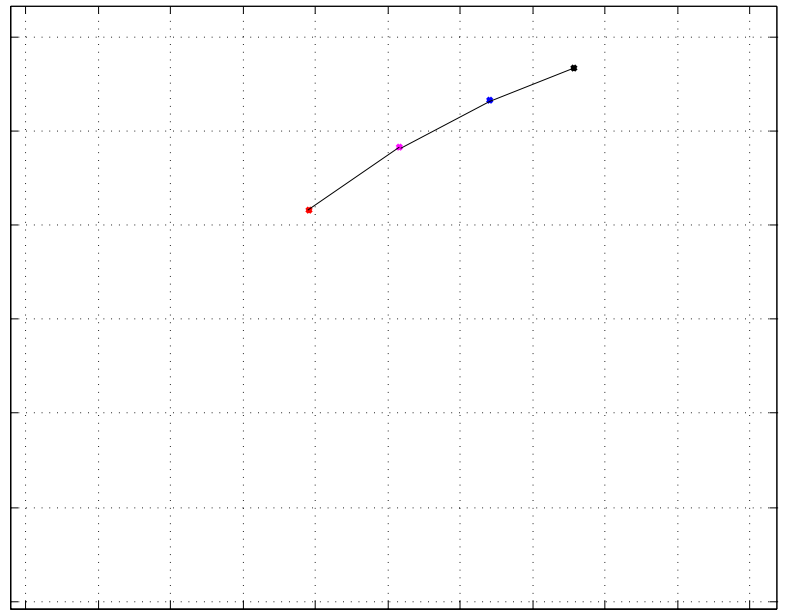

Figure 14. Local Mode when G2 is a WTG Source: GE Energy (C2005. Used with Permission.

\section{ECONOMIC VALUE}

Development of multiple large wind projects in the Hydro Québec system presents significant transmission interconnection challenges. Hydro-Québec's system, which has a winter peak of 35,000 MW, is geographically dispersed. Major hydro generation is up to $1000 \mathrm{~km}$ remote from major load centers. The entire grid is asynchronous with neighboring systems in Canada and the US. The first region in Québec to be developed for wind generation is the Gaspé peninsula (Figure 15), which is several hundred kilometers from major load centers, has weak existing transmission infrastructure, and very limited local generation.

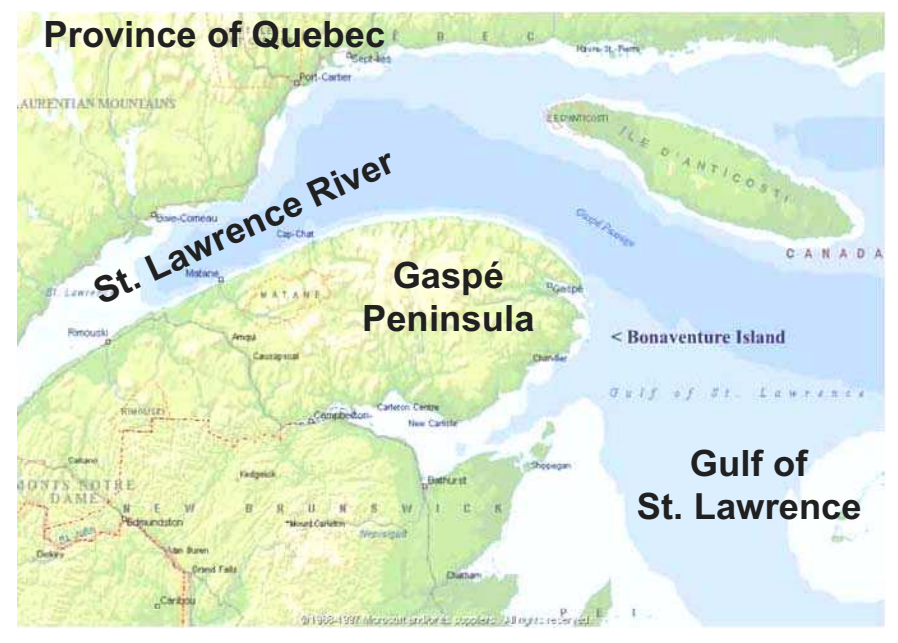

Figure 15. Gaspé Peninsula in eastern Quebec, Canada.
The initial wind tender solicited up to $1000 \mathrm{MW}$ of new wind generation projects for the region. Initial transmission planning studies performed by Hydro Québec TransÉnergie showed requirement for $\$ 288 \mathrm{M}$ US in transmission upgrades to accommodate this new wind generation. This included \$104M US for series, shunt and dynamic compensation. At the conclusion of the tendering process, GE wind generation was selected for all projects, totaling $990 \mathrm{MW}$. Transmission planning studies were then repeated, using updated models and wind generation controls consistent with the selected technology. The WTG equipment (including voltage regulation and LVRT features) significantly improved system performance, thereby reducing the need for other system reinforcements. The initial cost estimate for transmission reinforcement was reduced by about \$95M US [3].

\section{CONCLUSIONS}

Recent developments in wind generation technology have solved several of the serious problems posed by large wind farms connected to weak ac transmission grids. Coordinated voltage regulation of all individual WTGs in a large wind farm maintains constant voltage at the interconnecting bus, regardless of variations in wind power generation. LVRT technology enables wind farms to continue operation during and after severe faults or voltage depressions on the power grid. Power-electronic conversion and control technology incorporated into the generating system enables variable speed operation, while eliminating electromechanical power swing interaction with the grid. The combination of these features enable wind power plants to achieve stability performance that can exceed that of conventional synchronous generations of the same rating, installed at the same locations.

\section{REFERENCES}

[1] N. W. Miller, J. J. Sanchez-Gasca, W. W. Price, R. W. Delmerico, "Dynamic Modeling of GE 1.5 and 3.6 MW Wind Turbine-Generators for Stability Simulations", Proc. Power Engineering Society General Meeting. Toronto, Ontario. Canada, July 2003.

[2] M. Klein, G.J. Rogers, P. Kundur, "A Fundamental Study of Inter-Area Oscillations in Power Systems", IEEE Trans. on Power Systems, Vol. 6, No. 3, Aug. 1991, pp. 914-921.

[3] R. Champagne, M. Lamothe, S. Paquette, "Grid Connection of Large Wind Power Plants in Hydro-Quebec's System," WindPower '05, Denver Colorado, USA, May 16, 2005.

\section{BIOGRAPHIES}

Richard Piwko (M'76, F'96) is a Principal Consultant with GE Energy in Schenectady, NY. His responsibilities include management of large-scale system studies, power plant performance testing, control system design, and analysis of interactions between turbine-generators and the power grid. $\mathrm{He}$ recently contributed to GE's development of the Variable Frequency Transformer (VFT), a new technology for transferring power between asynchronous power grids. Mr. Piwko is a Fellow of the IEEE and has served as chairman of the IEEE HVDC \& FACTS subcommittee and as chairman of the IEEE Transmission and Distribution Committee. 